\title{
O RETORNO DO PÊNDULO: SERVIÇO PÚBLICO E EMPRESA PRIVADA. O EXEMPLO BRASILEIRO
}

O direito público brasileiro reflete, em sua evolução histórica, a alternativa de tendências que se aproximam dos parâmetros comparativos no plano internacional.

No período colonial, o absolutismo concentrava no poder monárquico o domínio da ordem econômica com a finalidade precípua de captação de recursos para o Erário Real.

As companhias ou empresas do período pré-colonial destinadas à manufatura, como as tapeçarias francesas, ou visando à conquista de novas terras, ou à busca de matérias-primas, de que foram modelos as Companhias de Índias Orientais e Ocidentais, como os empreendimentos portugueses ultramarinos, não se confundem com as experiências de capitalismo do Estado, que exprimem a prestação virtual de serviços de utilidade pública.

Eram, por excelência, investimentos da Coroa destinados a alcançar, em complemento à conquista de mares e terras desconhecidas, novas fontes de suprimento para os mercados europeus, mediante intercâmbio e importação de mercadorias.

O primeiro modelo de participação conjunta de capital público e privado, ainda que sem a modalidade moderna da sociedade de economia mista, se identifica, entre nós, no Alvará de 12 de outubro de 1808, com o qual D. João VI autorizou a criação do primeiro Banco do Brasil com capitais privados, a que se veio associar a Coroa em 1812.

É, porém, somente na segunda metade do século XIX, que a mobilização de capitais privados para a exploração de atividades de interesse coletivo se apresenta e assume aspecto significativo.

A expansão das cidades e a demanda popular reclamavam o apelo a processos de tecnologia e a recursos de capital, para o atendimento de necessidades coletivas fundamentais.

Era mister que os trilhos das estradas de ferro abrissem caminho para a ocupação pioneira de áreas internas, ligando centros de produção a centros de consumo. A iluminação pública, inicialmente a gás incandescente, transformou-se com a chegada da eletricidade. $\mathrm{O}$ ciclo de comunicações se inaugurava com a presença do telefone. $\mathrm{Ne}-$ 
cessidades vitais das comunidades organizadas exigiam serviços de água, esgoto e equivalentes.

Para o atendimento destas medidas essenciais, a administração pública não dispunha de condições próprias, desaparelhada que estava de meios específicos adequados.

Daí o apelo à iniciativa privada, convocando, a serviço do interesse geral, tecnologia e capital e, de forma dominante, a contribuição estrangeira.

Nascem, no final do século, os primeiros contratos de obras públicas que evoluem, como forma de amortização e remuneração do capital investido pela empresa privada, para firmar o modelo que iria se consolidar no sistema de concessões de serviço público, de formação contratual típica, inspirada no modelo francês da época.

Mais tarde, por influência em grande parte do exemplo regulamentar do direito norte-americano, o regime do serviço pelo custo viria a ordenar o processo de tarifas condicionadas pelo controle governamental.

A velocidade do progresso científico e o crescimento populacional das metrópoles, aprofundando, no primeiro quartel deste século, a necessidade de continuada atualização de serviços públicos essenciais, contribui para tornar nítidas duas variantes: de um lado, a mutabilidade dos contratos permitindo a modernização técnica das cláusulas de serviço e, de outra parte, a garantia da estabilidade econômico-financeira das concessões (cláusulas financeiras).

Firmou-se, em consequiência, o poder regulamentar do concedente, superando a regra da inviolabilidade bilateral do pacto, reservando-se, em contrapartida, ao concessionário a sobrevivência da comutatividade do contrato com o direito ao equilíbrio financeiro, mediante revisão periódica das tarifas segundo o custo real do serviço.

A partir da terceira década do século, a crise oriunda, sobretudo, do desequilíbrio do primeiro após-guerra, recruta a ação estatal para os novos direitos que começam a ingressar no elenco das garantias fundamentais.

$\mathrm{Na}$ década de 20 são criadas entidades públicas destinadas à prestação, ainda elementar, de serviços de previdência social e, com o movimento revolucionário de 1930, a União acelera a proteção aos direitos sociais e inaugura a atividade intervencionista no campo da economia produtiva.

A empresa pública, com os lineamentos básicos que a distingue, ingressa na vida econômica nacional com o Instituto de Resseguros do Brasil, em 1939, a Companhia Siderúrgica Nacional, em 1941, a Companhia do Vale do Rio Doce, em 1942. A estas se seguiram, em 1943, a Companhia Nacional de Álcalis, a Companhia Hidrelétrica do São Francisco, em 1945 e a Fábrica Nacional de Motores, em 1946.

A Constituição de 1934 prevê, pioneiramente, o capítulo da Ordem Econômica e Social. A liberdade econômica é garantida em limites que preservem os princípios da justiça e as necessidades da vida nacional de modo a possibilitar a todos existência digna (art. 115).

Por motivo de interesse público e mediante lei especial, admite-se o monopólio, pela União, de determinada indústria ou atividade econômica (art. 116), o controle estatal de exploração de recursos naturais, a par da regulação das relações de trabalho.

Após o interregno do período revolucionário instaurado em 1937 e com o restabelecimento do Congresso Nacional, a lei federal instituiu novas empresas públicas, 
entre as quais sobressaem a Petróleo Brasileira S.A. - Petrobrás (1953) com o monopólio estatal na área, e a Eletrobrás - Centrais Elétricas Brasileiras (1961), empresa holding do sistema federal de eletricidade.

Em setembro de 1981, recenseamento oficial - considerado apenas o plano federal - arrolava 530 pessoas jurídicas públicas, de teor econômico, inclusive autarquias, fundações e entidades paraestatais. Delas, 360 se constituíam sob forma societária de primeiro grau, ou subsidiárias, em todas predominando o capital público.

É certo que, nada obstante a expressão destes números, subsiste o sistema de sociedade aberta e de economia de mercado, que é de nossa tradição política, no qual a iniciativa econômica pública é, por definição constitucional, complementar da iniciativa privada, obedecendo ao princípio da subsidiariedade.

Acresce que o juízo de oportunidade e conveniência da atividade econômica pública é matéria privativa do legislador (princípio da reserva legal) e cada empresa estatal encontra na lei que a constitui o campo específico de atividades que não pode ultrapassar (princípio da especialidade).

A lei administrativa é a fonte primária tanto da criação como da funcionalidade da intervenção do Estado na economia.

A lei poderá adotar, por motivos de flexibilidade operacional, o modelo das sociedades privadas, tomado de empréstimo ao direito comercial, de tal forma que, na síntese de Massimo Severo Giannini, "el derecho privado, expulsado por la puerta, volvia a entrar por la ventana" (1). A opção pela personalidade de direito privado é, na hipótese, apenas um recurso técnico que não desnatura a finalidade pública do intervencionismo estatal. A sociedade do Estado não é tão-somente um fator econômico. É, essencialmente, um fato político.

Nas empresas estatais (como tais entendidas as empresas públicas e as sociedades de economia mista) a forma é privada, mas o substrato é público.

A personalidade de direito privado e a liberdade de gestão empresarial atuam como efeito centrífugo, distanciando-as do modelo centralizador. Contudo, a finalidade pública a que se destinam e a supervisão ministerial a que se submetem operam um efeito centrípeto, que as coloca como satélites do sistema da administração pública direta.

Tal como as autarquias e as fundações públicas, que são outras modalidades de entes paraestatais, a administração indireta, sem embargo da personalidade jurídica própria e da relativa autonomia funcional, está disposta, conforme a definição de Hely Lopes Meirelles, "paralelamente ao Estado, ao lado de Estado" (2).

$\mathrm{Na}$ descrição de Hanson, "a empresa pública não é um negócio comum, no qual o Estado mantém o capital; é uma agência de desenvolvimento econômico" (3).

A atual Lei de Sociedades por Ações (Lei n. 6.404, de 1976) reafirma o princípio de que "a constituição da companhia de economia mista depende de prévia autorização legislativa" (art. 236), subordinando-se à disciplina comercial, "sem prejuízo das disposições especiais de lei federal" (art. 235).

Jamais, no entanto, uma sociedade de economia mista será uma típica sociedade comercial privada. A mesma lei societária, dispondo no sentido de que "a pessoa jurídica que controla a companhia de economia mista tem os deveres e responsabilidade do acionista controlador", adianta de logo a diferença capital de que "poderá 
orientar as atividades da companhia de modo a atender ao interesse público que justificou a sua criação" (art. 238).

Esta norma retrata o temperamento que sofre, na companhia de economia mista, o princípio da affectio societatis, que exprime, na sociedade privada, a comunhão dos acionistas.

Na sociedade de economia mista não é apenas a posição majoritária que discrimina os acionistas. Há uma nítida diversificação entre o estado-acionista controlador, que visa a exercer uma missão de interesse público relevante e o investidor privado, legitimamente inspirado pelo exclusivo espírito de lucro. Há um conflito latente entre os dois pólos de interesse, ou seja, entre a permanência do acionista estatal, inerente à própria natureza da companhia de economia mista (cujo objeto social se confunde com a prestação de um serviço público lato) e a flutuação dos acionistas privados minoritários, precisamente atraídos pela rentabilidade das ações e suas cotações bursáteis (as blue chips das bolsas de valores).

De tal forma o Estado como acionista perturba o equilibrio da sociedade que a Lei de S.A. instituiu um direito especial de recesso para os acionistas "sempre que pessoa jurídica de direito público adquirir, por desapropriação, o controle de companhia em funcionamento (...) salvo se já se achava sob controle, direto ou indireto, de outra pessoa jurídica de direito público, ou no caso de concessionária de serviço público" (art. 236, parágrafo único).

E que a aquisição compulsória do controle desqualifica os objetivos originais da companhia e quebra a comunhão de interesses entre os sócios, sobrepondo-lhes o interesse público que passa a dominar a condução dos negócios da sociedade. As exceções previstas confirmam a regra, posto que nas companhias já sob controle público, ou nas concessionárias, a condição de um serviço público virtual precede ao ato expropriatório.

Qualifica a atual Lei das S.A., normas peculiares às companhias de economia mista. A par da já mencionada necessidade de prévia autorização legislativa, cumpre à respectiva lei institucional determinar o objeto social que devem perseguir (art. 237). Nelas é obrigatória a existência de conselho de administração e de conselho fiscal permanente, assegurada a participação da minoria (arts. 239 e 240).

Matéria relevante e de notória atualidade é o controle das empresas públicas e sociedades de economia mista, que não se exaure nos instrumentos comuns de proteção aos acionistas e aos credores.

O extraordinário relevo assumido pela administração indireta coloca na ordem do dia a eficiência do poder de mando da autoridade pública sobre os antes personalizados que gravitam em torno da administração direta.

Não se trata, apenas, do controle contábil, ainda que relevante. Nesse particular se associam aos órgãos internos da própria sociedade os instrumentos de supervisão ministerial e os de fiscalização orçamentária e financeira, a cargo do Tribunal de Contas.

Maior destaque representa, porém, a integração das empresas públicas e sociedades de economia mista no planejamento global da administração e da economia pública e o controle de resultados em função dos objetivos programáticos da política econômica e financeira do Estado. 
A atual Constituição brasileira, promulgada em 5 de outubro de 1988, reafirma o princípio da ordem econômica, fundada nos princípios, que se completam e harmonizam, da valorização do trabalho humano e da livre iniciativa, conforme os ditames da justiça social, ressalvando a presença da atividade econômica do Estado quando necessária em face dos imperativos da segurança nacional ou de relevante interesse coletivo, conforme definição em lei (arts. 170 e 173).

Ao Estado incumbe, como agente normativo e regulador da atividade econômica, exercer, na forma da lei, as funções de fiscalização, incentivo e planejamento, sendo este determinante para o setor público e indicativo para o setor privado (art. 174).

A curva ascendente de expansão da ação direta do Estado na atividade econômica e social alcança o seu ápice no início da década de 80.

Até 1930 os órgãos paraestatais não iam além de 17, elevando-se a 70 na década dos anos 50, para atingir a cifra de 582 nos últimos anos de período em que se expandia a participação estatal visando ao desenvolvimento econômico e à ocupação de setores em que se revelava ineficaz ou ausente a iniciativa privada. Este foi o estímulo da presença estatal na siderurgia e na petroquímica, a par do monopólio estatal nos setores de petróleo e de telecomunicações.

A limitação de serviços públicos e a tendência de retomada da abertura da ordem econômica, a par do crescimento na demanda de serviços essenciais, conduzem a uma crescente política de retração na atividade pública empresarial, com a busca de maior produtividade em áreas acessíveis à economia privada.

Não somente o Estado deve ser menor - e, por via de conseqüência, mais eficiente - como, sobretudo, deve concentrar-se no atendimento de necessidades básicas da coletividade, sob o signo da modernidade e da satisfação de direitos coletivos e difusos.

O Estado deve ser o elemento condutor do progresso da sociedade, mas não será necessariamente o agente ativo ou exclusivo no oferecimento de serviços à comunidade.

De outra parte, refletem-se na política nacional as significativas experiências internacionais, tanto nos países desenvolvidos, com o exemplo da Inglaterra e da França, como em países em desenvolvimento, à semelhança do México e do Chile.

Segundo relatório de 1994 do Banco Mundial, no período de 1988 a 1992, 25 países em desenvolvimento realizaram programas de privatização, no valor total de US $\$ 61,6$ bilhões, com dois terços concentrados em setores da infra-estrutura.

O primeiro passo, ainda modesto, de inversão da tendência expansionista da administração pública brasileira se manifesta, em julho de 1979, quando o Decreto n. 83.740 adota o Programa Nacional de Desburocratização que, a partir de 1981, define a política restritiva na criação de novas entidades paraestatais e estabelece as primeiras diretrizes de transferência de empresas públicas para o setor privado. 
Em 1985, o Decreto n. 91.991 aperfeiçoa o programa com a criação do Conselho Interministerial de Privatização, ao qual sucede, em 1988, o Conselho Federal de Desestatização, nos termos do Decreto n. 95.886 .

Foram, até 1989, incluídas no esquema 24 empresas, das quais 15 foram alienadas, liquidadas 3 , incorporadas 2 e 14 transferidas ao plano estadual.

Segundo dados oficiais, no período de 1979-1985, no plano federal, 20 empresas foram privatizadas, 3 transferidas a governos estaduais, outras 3 foram objeto de fusão, 14 incorporadas e duas outras convertidas em órgãos da administração direta, no total de 42 transformações.

Uma terceira etapa se instaura com o advento do governo Collor, que regula o Programa Nacional de Desestatização mediante a Medida Provisória n. 155/90, convertida na Lei n. 8.031, de 12 de abril do mesmo ano, que subsiste como padrão da política de privatização.

O relatório do Tribunal de Contas da União sobre a gestão financeira de 1994 revela que, no período de 1990 a 1994, 65 empresas estatais foram incluídas no Programa Nacional de Desestatização, sendo que 33 foram transferidas à iniciativa privada e estão em curso os processos de alienação das demais 32 .

Das 33 alienadas, 20 eram controladas pela União, que somente detinha participação minoritária nas 13 restantes. A alienação gerou o montante de US $\$ 8,2$ bilhões, dos quais $67,8 \%$ provenientes da venda de empresas do setor siderúrgico.

É mister destacar, no desenvolvimento do programa de privatização, certas peculiaridades que distinguem sua execução.

No total de recursos arrecadados com a alienação foi menor a parcela captada em moeda corrente, prevalecendo o pagamento, mediante novação, com o desembolso de títulos da dívida pública e créditos contra a União. De qualquer forma, foi significativa a liberação da responsabilidade da União na cobertura do passivo pendente das empresas e a dispensa de novos investimentos nos setores privatizados.

Associava-se, assim, o benefício de amortização da dívida mobiliária federal com o alívio na caixa do Tesouro Nacional.

O atual governo da República manifesta o propósito de ampliar a exigibilidade de pagamento em moeda corrente e fez incluir no Programa Nacional de Desestatização empresas de porte tanto no setor elétrico como na mineração.

No programa brasileiro de privatização, a partir de 1991, destaca-se a presença, como adquirentes, de fundos de pensão que, segundo dados da Associação Brasileira de Previdência Privada, investiram mais de 2 bilhões, como compradores, na maioria das empresas privatizadas, compartilhando com bancos particulares a condição de maiores investidores.

A participação de empregados na compra das ações, embora facilitada, como estímulo à pulverização das ações, não alcançou resultado significativo.

III

O programa de privatização de empresas estatais não se resume à abstenção do Estado em áreas até então ocupadas que revertem à iniciativa privada. 
Antes qualifica uma evolução nas relações entre o serviço público e a iniciativa que passam a se associar no objetivo final de prestação de serviços à comunidade.

O pêndulo que favorecia o domínio público sobre a economia, em áreas qualificadas, reverte um benefício da exploração privada de atividades produtivas, ainda que sob a vigilância do poder de polícia administrativa.

$\mathrm{Na}$ transição do tempo, o século XVIII exprimiu a tônica de garantia de direitos individuais e de liberdades públicas como reação ao absolutismo do poder.

A igualdade de todos perente a lei é a regra de ouro do liberalismo e o modelo de constitucionismo que reconhece o indivíduo como titular de direitos subjetivos.

Na passagem para o século XIX e, notadamente, na primeira metade do século $\mathrm{XX}$, desenha-se a insuficiência de igual tratamento entre desiguais.

$\mathrm{Na}$ ironia de Anatole France, a lei reconhece igualmente a pobres e ricos o direito de dormir debaixo das pontes de Paris.

Consagra-se, progressivamente, o reconhecimento de direitos sociais e a efetividade de acesso aos bens da fortuna.

O trabalhador e o cidadão assumem a qualidade de sujeito de direitos ao mesmo tempo em que a empresa se torna centro de participação na vida comunitária.

Mais ainda evolui a relação jurídica entre o Estado e os administrados na medida em que a proteção de direitos coletivos e difusos incorpora no elenco de titulares de direitos a figura do consumidor.

A propriedade privada retoma, de certa forma, sua autonomia, obscurecida pela exacerbação do intervencionismo estatal na economia, mas fica nítida a subordinação de sua atividade aos pressupostos da função social que dela se exige.

Em termos contemporâneos o direito público passa a refletir - e são modelo desta tendência as novas constituições do final de século - duas vertentes específicas: a política de privatização e de desburocratização da máquina estatal e o fortalecimento da associação entre a iniciativa privada e o serviço público.

De outra parte, valoriza-se a comunhão entre nações e regiões, superando barreiras nacionais ou limitações de autonomia federativa.

Os mercados comuns e as circunscrições autônomas são formas atuais de crescente participação asima do isolamento do nacionalismo.

No direito brasileiro a recepção destas influências se manifesta, ao mesmo tempo, no favorecimento da política de privatização e na aceleração da presença no Mercosul que associa nações vizinhas na América Latina.

\section{IV}

A Constituição brasileira de 1988, sensível aos ventos novos, recebe os eflúvios da reformulação de alguns de seus preceitos fundamentais no plano da ordem econômica e social.

As recentes Emendas Constitucionais de n. 5 a 8, promulgadas em 15 de agosto último, autorizam reformas legislativas tendentes à abertura, ao capital privado, de atividades antes reservadas à exploração estatal, ampliando o instituto da concessão. 
Outras emendas, em curso no Senado, após sua aprovação na Câmara de Deputados, deverão limitar o monopólio estatal no petróleo e nas telecomunicações, permitindo a presença da empresa privada.

Também o acesso do capital estrangeiro estará facilitado na medida em que a definição de empresa nacional venha a retomar, como paradigma, a sede da pessoa jurídica, independentemente da natureza do capital da sociedade.

\section{V}

Merece destaque, como expressiva valorização da iniciativa privada em áreas peculiares à atividade estatal, a reformulação operada nos serviços de energia elétrica, com o advento da reforma da legislação regulatória das concessões de serviço público, nos termos da Lei n. 8.987, de 13 de fevereiro de 1995 e da Lei n. 9.074, de 7 de julho de 1995.

Com apoio nos textos novos, as empresas estatais concessionárias de serviços de produção de energia elétrica estão adquirindo condições para a retomada da construção de usinas paralisadas pela incapacidade financeira de concluí-las e colocá-las em operação.

Ainda uma vez mais o direito administrativo foi buscar inspiração no direito privado para importar, do direito mercantil, a modalidade de associação de capitais, sob o molde de consórcio, previsto no art. 278 da Lei de Sociedade por Ações (Lei n. 6.404, de 15 de dezembro de 1976).

Sob esta figura associativa e, ainda, como parceria, o grupo de empresas privadas assume a responsabilidade financeira pela conclusão das obras mediante a garantia, para uso próprio, de determinada parcela de energia a ser produzida.

O consórcio é constituído para uso exclusivo da energia pelos consorciados, ou para produção independente, admitindo-se a transferência das concessões de produção para os novos financiadores da obra pública.

Modelos equivalentes serão admissíveis nos serviços de telecomunicações ou de exploração de petróleo na medida em que venha a prevalecer, nas reformas constitucionais em curso, a abertura dos monopólios estatais, e o tratamento do capital estrangeiro.

As Constituições brasileiras que se sucederam, na República, são episódios ilustrativos de alternância das variações do pêndulo institucional.

A primeira Constituição, em 1891, modela a passagem do regime monárquico para o republicano e a forma representativa de governo, adota o sistema federativo e mantém a plenitude do direito de propriedade, abstendo-se de intervir na economia.

Vencida a etapa do Governo Provisório, oriundo da Resolução de 1930, o regime democrático que se restaura com a Constituição de 1934 contempla entre seus postulados o bem-estar social econômico e veda o exercício do direito de propriedade contra o interesse geral ou coletivo.

Condiciona a ordem econômica aos princípios da justiça e às necessidades de vida nacional, porém, respeitados estes limites, firma como alicerce a garantia da liberdade econômica. 
Novo interregno da continuidade democrática leva, como antídoto, a que seja outorgada a Constituição de 1937 que, invocando o risco de infiltração comunista, absorve o atrativo da concentração de poder, segundo modelos europeus de direita.

O capítulo da Ordem Econômica legitima a intervenção do Estado no domínio econômico para suprir deficiência da iniciativa individual e coordenar os fatores de produção.

A intervenção no domínio econômico estava prevista como forma de controle, de estímulo ou de gestão direta.

A partir de então, o pêndulo se dirige, com maior intensidade, ao pólo da política intervencionista, como evidencia a assinalada expansão de crescimento das empresas estatais.

A Constituição de 1946 é marcada, pelo retorno à prevalência dos direitos fundamentais e das liberdades políticas e, no plano da ordem econômica e social, visa à conciliação da liberdade de iniciativa com a valorização do trabalho humano.

A intervenção no domínio econômico ou o monopólio de determinada indústria ou atividade, tendo como base o interesse público, poderão ser estipulados em lei especial, que, ademais, deverá reprimir os abusos do poder econômico.

$\mathrm{O}$ uso da propriedade ficava condicionado ao bem-estar social, podendo a lei determinar-lhe a justa distribuição, com igual oportunidade para todos.

O Estado é chamado a colaborar na prestação de serviços que, sem prejuízo do papel relevante da iniciativa privada, possam tornar efetivo o direito de todos à Educação e à Cultura.

Outra página da história constitucional brasileira escreve-se na Constituição de 1967, logo emendada substancialmente em 1969 e à qual se vão acrescer outras 26 Emendas Constitucionais, até 1985.

Subsiste, na sua vigência, a tendência intervencionista e de concentração de poder, sem embargo da garantia de direitos fundamentais e da continuidade formal do sistema representativo.

Por último, a Constituição de 1988, mais uma vez, exprime o movimento pendular, que, na sucessão de um período autoritário de governo, procura a volta aos princípios fundamentais de liberdade e de plenitude democrática.

Tomando, de certa forma, como paradigma, as diretrizes da Constituição portuguesa de 1976 e da Constituição espanhola de 1978 (ambas sucessivas a um regime de feição totalitária) autodenomina-se como o código de um Estado Democrático de Direito e, em proclamação que antecede o seu texto, é batizada como Constituição Coragem ou Constituição Cidadã.

A latitude de suas promessas, pendentes de eficácia pela necessidade de infraestrutura legal, coloca, lado a lado, a livre iniciativa e o desenvolvimento nacional; o livre exercício da atividade econômica e a intervenção do Estado em defesa da segurança nacional e de relevante interesse coletivo; a coordenação, pelo poder público, do desenvolvimento urbano e da reforma agrária com a garantia da propriedade, respeitada sua função social; o dever do Estado no campo da Educação e da Saúde com a promoção privada de tais serviços.

Na extensa gama de suas promessas, a Constituição de 1988 caminha - tal como ocorreu com a Constituição de 1976 - a uma reavaliação de seus endereços progra- 
máticos e de sua efetiva funcionalidade, tanto pelo saneamento de suas próprias contradições como ainda para a recepção da experiência internacional.

A abertura da economia e a relativa retirada da presença do Estado na prestação de serviços econômicos é uma das manifestações desta dança do pêndulo entre extremos em busca do equilíbrio estável da perfeição.

\section{BIBLIOGRAFIA}

1 - MASSIMO SEVERO GIANNINI - Atividades economicas publicas y formas juridicas privadas, in La empresa publica, coletânea de estudos del Real Colégio de España - tomo I, 1970, p. 103.

2 - HELY LOPES MEIRELLES - Estudos e Pareceres de Direito Público - vol. III - p. 13.

3 - A. H. HANSON - Public enterprise and economic development - Londres - $1960-$ p. 441 . 